Esta revista forma parte del acervo de la Biblioteca Jurídica Virtual del Instituto de Investigaciones Jurídicas de la UNAM www.juridicas.unam.mx

http://biblio.juridicas.unam.mx

\title{
La publicidad política televisiva en el proceso electoral federal de 2012 en México
}

\author{
Julio Juárez Gámiz* \\ José Antonio Brambila**
}

\section{Sumario:}

I. Introducción

II. Publicidad política sin información

III. Monólogo publicitario

IV. Personalización de la política

V. Conclusiones

VI. Fuentes consultadas

Investigador en el Centro de Investigaciones Interdisciplinarias en Ciencias y $\mathrm{Hu}-$ manidades (CEIICH) de la UNAM e integrante del Sistema Nacional de Investigadores Nivel I. Es licenciado en psicología por la UNAM y tiene una maestría (MA) y un doctorado $(\mathrm{PhD})$ en Comunicación Política por la University of Sheffield, Inglaterra.

** Maestro en Ciencia Política por El Colegio de México y licenciado en Comunicación por la Universidad Panamericana. En 2011 ganó el premio nacional de ensayo del Canal del Congreso en México. 
Esta revista forma parte del acervo de la Biblioteca Jurídica Virtual del Instituto de Investigaciones Jurídicas de la UNAM www.juridicas.unam.mx

\section{Resumen:}

La presente investigación tiene como objetivo analizar el contenido y estructura de la publicidad política televisiva producida por los partidos durante el proceso electoral federal de 2012. El principal objetivo del estudio es evaluar una de las principales herramientas de comunicación en el actual modelo de comunicación política mexicano: el spot político. En este estudio se evaluaron los 308 mensajes (spots) producidos por los siete partidos políticos durante el proceso electoral federal de 2012. Los hallazgos presentados se evalúan a la luz de los cambios asociados directa o indirectamente a la reforma electoral 2007-2008.

Palabras clave: comunicación política, spotización, elecciones, publicidad televisiva. 


\section{Introducción}

Por su importancia y centralidad en las democracias modernas, la publicidad política es uno de los principales objetos de observación electoral. En el caso mexicano dicha publicidad cobra relevancia toda vez que representa una importante fuente de información política para la ciudadanía. A manera de contexto veamos algunos datos. En el caso mexicano una parte importante del electorado (57\%) sigue con atención la campaña electoral y $42 \%$ dice prestar atención a la publicidad que los partidos políticos trasmiten a través de la radio y la televisión. Más de la mitad (60\%) asegura recordarla. ${ }^{1}$ No es de extrañar, por tanto, que la legislación electoral intervenga de manera directa en la manera en la cual los partidos políticos acceden a la radio y la televisión mediante un formato predominantemente publicitario.

La presente investigación tiene como objetivo analizar el contenido y estructura de la publicidad política televisiva producida por los partidos durante el proceso electoral federal 2012. ${ }^{2}$ Los hallazgos presentados se evalúan a la luz de los cambios estructurales y de contenido que, directa o indirectamente, están asociados a la reforma electoral 2007-2008 (de aquí en adelante la reforma).

Antes de la reforma, el acceso de partidos políticos a la publicidad en radio y televisión durante el proceso electoral se determinaba por la cantidad de recursos públicos que dichos actores destinaban a la compra de tiempo aire en radiodifusión. A partir de la reforma hay un modelo en el que prevalece, como valor último, la equidad, aun por encima de la libertad de contratación de los partidos políticos, para lo cual el acceso a la radiodifusión se encuentra mediado por el Instituto Federal Electoral (IFE), convirtiéndose en la autoridad que administra el tiempo de los partidos en los medios.

El apartado A del artículo 41 constitucional señala que el IFE es la única autoridad capaz de administrar el tiempo televisivo de los parti-

1 Posicionamiento público del Instituto Federal Electoral. Resultados de la encuesta poselectoral realizada por el Centro de Investigación y Docencia Económicas (CIDE), 13 de octubre de 2009, pp. 68-70.

2 La información presentada en este artículo se basa en un análisis de los spots que los siete partidos políticos produjeron durante la elección federal de 2012. A cada spot se aplicó un protocolo de 47 variables (de contenido y estructura). 
Esta revista forma parte del acervo de la Biblioteca Jurídica Virtual del Instituto de Investigaciones Jurídicas de la UNAM

dos políticos, por lo que se establece la prohibición de contratar o adquirir, por los partidos políticos o por terceros interesados, tiempo en radiodifusión (en cualquier modalidad). Asimismo, los artículos 56 y 58 del Código Federal de Instituciones y Procedimientos Electorales (Cofipe) establecen que la transmisión de los mensajes de los partidos se debe realizar dentro de un esquema de distribución del tiempo fiscal dejando fuera el papel del dinero en la contratación de espacios en radio y televisión.

De acuerdo con el artículo 56 del Cofipe, el IFE reparte el tiempo aire disponible para los partidos políticos en apego a un criterio que distribuye el $30 \%$ de manera equitativa y el $70 \%$ de acuerdo al porcentaje de votación obtenido en la elección inmediata anterior para diputados federales. La producción de los mensajes corre a cargo del partido político y la única razón que impediría la transmisión de un mensaje ex ante serían las deficiencias técnicas que, al momento de ingresar al pautado, detectara el propio Instituto.

Asimismo, de acuerdo con los incisos $a, c$ y $d$ del apartado A del artículo 41 constitucional, a partir del inicio de las precampañas y hasta el día de la jornada electoral, quedarán a disposición del IFE 48 minutos por canal de televisión y estación radiofónica, que se distribuye de la siguiente manera: 41 minutos entre los partidos políticos y 7 minutos "para los fines propios del Instituto y de otras autoridades electorales". La distribución se hace con un máximo de tres minutos por hora de transmisión de las 06:00 a las 24:00 horas.

$\mathrm{Al}$ interior del IFE, el organismo encargado de definir las pautas es el Comité de Radio y Televisión. De hecho, en la fracción 2 del artículo 73 del Cofipe se establece que el Comité tiene la facultad de determinar por cada mensaje la estación o canal, así como el día y hora en que deben transmitirse. En la fracción 3 del mismo artículo se imposibilita a los concesionarios y permisionarios cualquier alteración o modificación a dichas pautas. En este sentido, es importante señalar que a pesar de que la legislación (artículo 41 constitucional y artículo 56 del Cofipe) contempla la transmisión de spots de 30 segundos, uno y dos minutos, el Comité estableció que los spots producidos por los partidos políticos durante el proceso federal electoral de 2012 fueran de 30 segundos (ACRT/028/2011).

Respecto al contenido de la publicidad política, antes de la reforma, la prohibición a la calumnia de personas o denigración de instituciones estaba considerada únicamente en el Cofipe (artículo 38, 
Esta revista forma parte del acervo de la Biblioteca Jurídica Virtual del Instituto de Investigaciones Jurídicas de la UNAM

inciso P). Ahora, tras la reforma, dicha prohibición se elevó a rango constitucional: "(en la propaganda) que difundan los partidos deberán abstenerse de expresiones que denigren a las instituciones y a los propios partidos, o que calumnien a las personas" (artículo 41, Inciso III, Apartado C).

En cuanto a los spots que se analizan en este artículo, se toman en consideración los 308 spots (ejecuciones) producidos por los siete partidos políticos durante el proceso electoral federal de $2012^{3}$ (véase figura 1). Por tanto, el presente trabajo se basa en un censo de spots para las campañas presidencial y legislativa.

Las ejecuciones analizadas están distribuidas de la siguiente manera: del Partido Acción Nacional (PAN) se registraron 81 (26\% del total); del Partido Revolucionario Institucional (PRI) 111 (36\%); Partido de la Revolución Democrática (PRD) 18 (6\%); Partido del Trabajo (PT) 27 (9\%); Partido Verde Ecologista de México (PVEM) 16 (5\%); Movimiento Ciudadano (MC) 24 (8\%), y Partido Nueva Alianza (PANAL) $31(10 \%) .{ }^{4}$

Figura 1. Spots producidos por partidos políticos.

Elección presidencial 2012
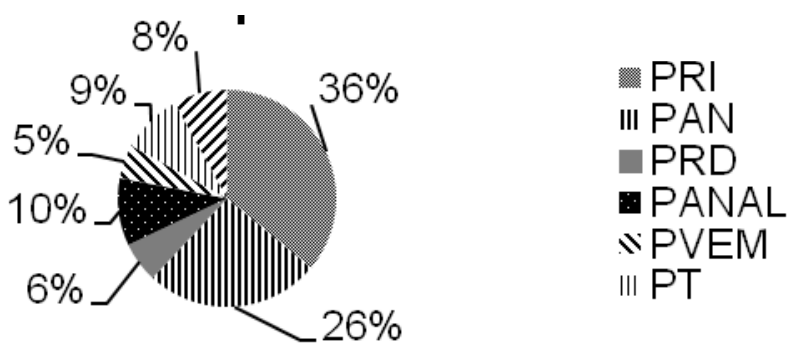

En suma, este artículo analiza el contenido y la estructura de la publicidad televisiva que los partidos políticos producen y difunden a través del tiempo oficial. El principal objetivo del estudio es evaluar una de

3 Los spots que se analizan aquí fueron descargados de la página de pautas del IFE en http://pautas.ife.org. $m x /$, del 30 de marzo al 27 de junio de 2012.

4 Los hallazgos del estudio se presentan por partido político y no por coalición. Lo anterior responde, entre otras cosas, a que a partir de la reforma electoral de 2007-2008, los partidos políticos, estén o no coaligados, deberán captar los votos del electorado de forma individual y no, como sucedía anteriormente, por coalición política. 
Esta revista forma parte del acervo de la Biblioteca Jurídica Virtual del Instituto de Investigaciones Jurídicas de la UNAM

las principales herramientas de comunicación en el actual modelo de comunicación política. Dicha evaluación es crucial no sólo para generar rendición de cuentas y transparencia sobre un bien público, el tiempo oficial, sino sobre todo porque la calidad de información política que recibe el electorado por medio de la publicidad política se encuentra íntimamente relacionada con la calidad de la democracia.

El artículo está dividido en cuatro apartados que resumen las principales conclusiones de la Observación Electoral que realizó el Centro de Investigaciones Interdisciplinarias en Ciencias y Humanidades de la UNAM acerca de la publicidad política, mediante el financiamiento del IFE y la Secretaría de Gobernación que administró el Programa de las Naciones Unidas para el Desarrollo. Estos apartados son: ausencia de información política en la publicidad política; promoción, negatividad y contraste en los spots políticos; personalización de la política, y los hallazgos y las principales recomendaciones de la investigación.

\section{Publicidad política sin información}

En las democracias modernas la información política representa uno de los principales insumos que tienen los ciudadanos tanto para evaluar a sus gobernantes cuanto para tomar decisiones. Es por esto que la Constitución Política de los Estados Unidos Mexicanos (artículo 41) les concede a los partidos políticos, entidades de interés público, la promoción de la "participación del pueblo en la vida democrática... de acuerdo con los programas, principios e ideas que postulan”. Para la consecución de tal fin, el Estado los provee de prerrogativas que faciliten la consecución de los objetivos antes mencionados, entre dichas prerrogativas está el acceso a los medios masivos de comunicación (radio y televisión). Por tanto, los partidos tienen la obligación de difundir sus plataformas electorales, para así fomentar la participación electoral de los ciudadanos.

Siguiendo esta idea, para la presente investigación se extrajeron los seis principales grupos temáticos (clusters) que los siete partidos políticos desarrollaron en la plataforma electoral que registraron ante el IFE antes de la campaña (véase tabla 1), éstos son: 1) reforma del Estado; 2) seguridad; 3) política social; 4) economía; 5) política exterior, y 6) medio ambiente. Además de estos seis clusters temáticos, en 
Esta revista forma parte del acervo de la Biblioteca Jurídica Virtual del Instituto de Investigaciones Jurídicas de la UNAM

la investigación se incluyó otro más que fue definido como "estrategia electoral", es decir, spots cuyo tema principal no fuera ninguno de los seis anteriores, sino la presentación de acciones mediáticas planificadas con el objetivo de lograr un fin meramente electoral (quitar votos, mantener registro, comparar o atacar a los rivales, promover símbolos, valores y personas, entre otros). ${ }^{5}$

Como se observa en la tabla 1 , los resultados del estudio muestran que el cluster de "estrategias electorales" fue el más utilizado por todos los partidos políticos con 55.5\% de los spots, seguido por "seguridad pública", con $14.6 \%$ de las producciones; "política social”, 13.6\%, y "economía", 13\%. Los temas incluidos dentro de los grupos "reforma del Estado", "política ambiental” y "política exterior" fueron los menos tratados por los partidos.

5 Cabe resaltar que cada una de estas siete categorías temáticas (las seis extraídas de las plataformas electorales más "estrategia electoral") son mutuamente excluyentes, es decir, un mismo spot no fue codificado a la vez como de "seguridad" o de "política social", sino solamente en una categoría. 
Esta revista forma parte del acervo de la Biblioteca Jurídica Virtual del Instituto de Investigaciones Jurídicas de la UNAM

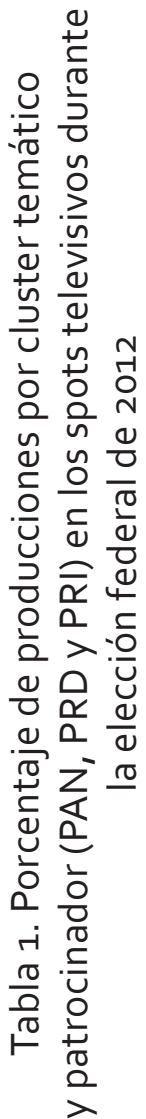

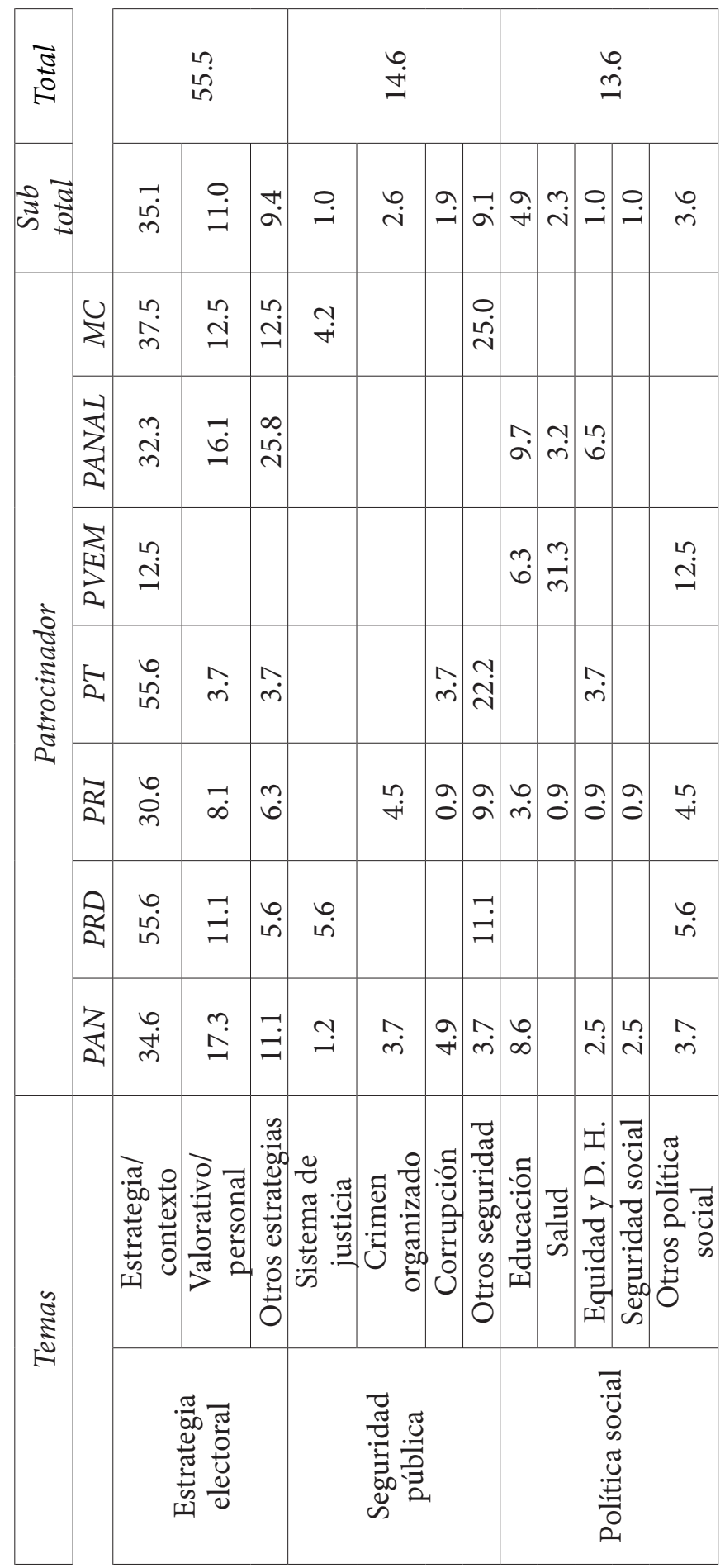


Esta revista forma parte del acervo de la Biblioteca Jurídica Virtual del Instituto de Investigaciones Jurídicas de la UNAM www.juridicas.unam.mx

http://biblio.juridicas.unam.mx

DOl: http://dx.doi.org/10.22201/iij.24487910e.2013.4.10041

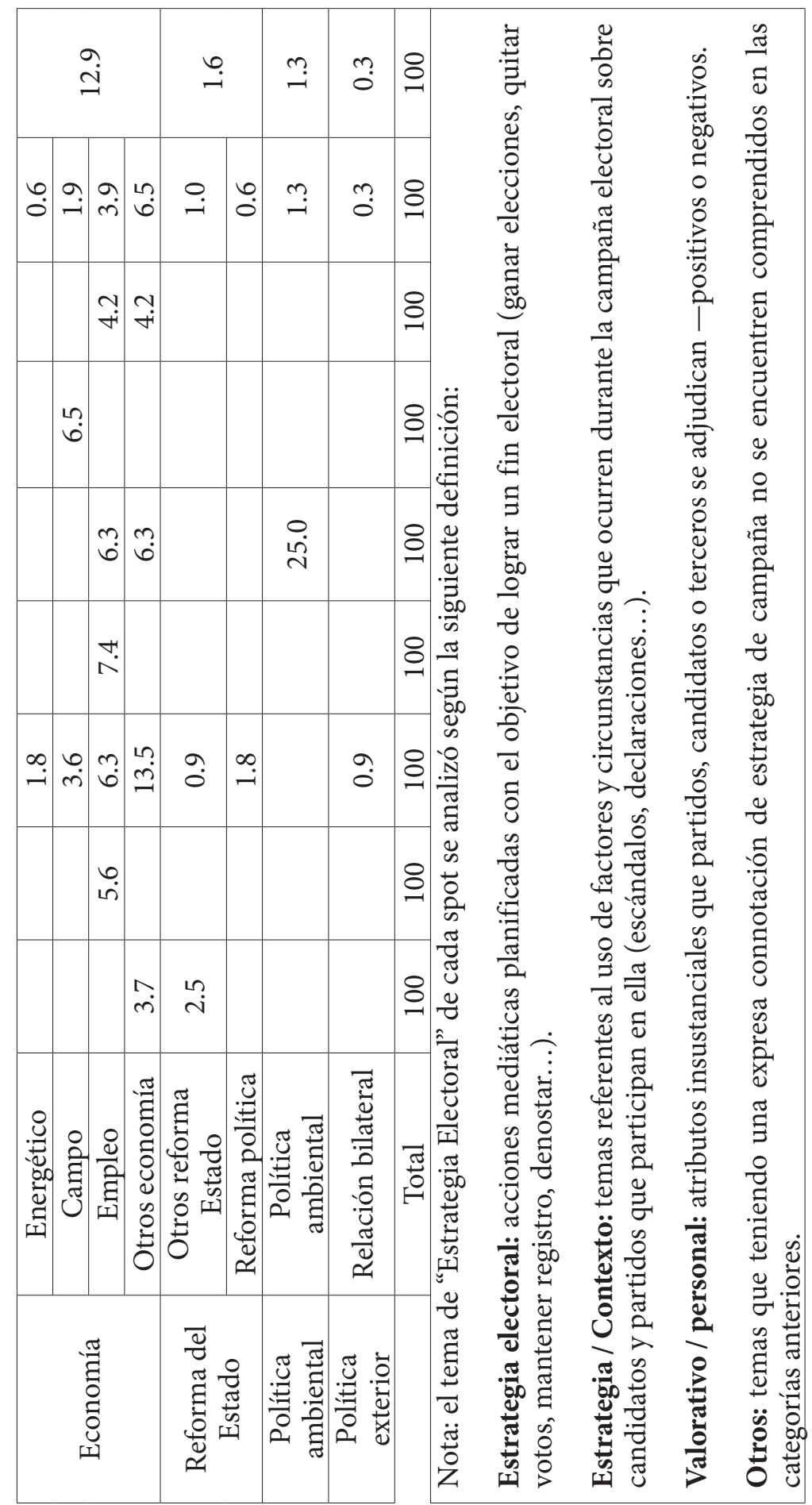


Esta revista forma parte del acervo de la Biblioteca Jurídica Virtual del Instituto de Investigaciones Jurídicas de la UNAM

De acuerdo con nuestra investigación, más de la mitad de los mensajes dejaron de lado las propuestas y soluciones a los problemas nacionales, ${ }^{6}$ pues se centraron en mensajes insustanciales o autorreferenciales, en ataques y descalificaciones, en vez de ofrecer información política de utilidad para el electorado. Del total de spots que utilizaron “estrategia electoral", la mayoría de las veces (35\%) fueron catalogados como "estrategia-contexto", es decir, spots con temas referentes al uso de factores y circunstancias que ocurren durante la campaña electoral sobre candidatos y partidos que participan en ella (escándalos, declaraciones, protestas, etcétera).

Como se observa en la tabla 1, el otro subtema del cluster "estrategia-electoral" es el "valorativo-personal", el cual se refiere a atributos insustanciales que partidos, candidatos o terceros se adjudican - positivos - o asocian a sus oponentes - negativos-. El PAN utilizó más veces este tipo de spots (17\%), su estrategia intentó posicionar a la candidata por medio de sus atributos personales, desde el inicio de la campaña, Josefina Vázquez Mota se presentó como una candidata distinta de sus contrincantes, dicha distinción se anclaba en características insustanciales y autorreferenciales carentes de una argumentación clara ("Josefina Diferente"), o en la referencia a su condición de género ("Josefina. La mujer tiene palabra").

El resto de los spots publicitarios (46\%) está distribuido entre los seis grupos temáticos arriba mencionados. Durante la elección cada uno de los siete partidos políticos se refirió con mayor profundidad a alguno de los seis tópicos. Por tanto, es posible identificar que cada agrupación política dirigió su campaña electoral a un grupo temático: el PRI se identificó con "economía" (25.2\% de sus spots); la coalición de izquierda (MC en $29.2 \%$, PT en $25.9 \%$ y PRD en $16.7 \%$ ) con el de "seguridad"; el PVEM (50\%), el PANAL (19.4\%) y el PAN (17.3\%) con el de "política social", y el PVEM con "política ambiental" (25\%).

${ }^{6}$ En este se sentido, la evidencia empírica disponible apunta que para el electorado los partidos políticos utilizan la publicidad para criticar a sus oponentes (39\%), difundir sus propuestas (33\%) o ambas (22\%). CIDE, op. cit., p. 67. En otro estudio se determinó que para $62 \%$ del electorado, los spots han sido poco o nada útiles para difundir su voto. Encuesta nacional Grupo Reforma, "Primeros efectos de campaña”, 6 de mayo de 2012, consultado el 10 de agosto de 2012 en http://gruporeforma-blogs.com/encuestas/? $p=1288$. 


\section{Mónologo publicitario}

La información política que recibe el electorado también se puede evaluar a la luz de las proposiciones (promoción, contraste y ataque) que los partidos políticos realicen en su publicidad política. Durante el proceso electoral federal los partidos políticos utilizaron en mayor medida los spots de promoción que los de ataque y contraste (véase figura 2). Sin embargo, de acuerdo con nuestra evidencia, esta preponderancia promocional no se puede considerar como una mayor obtención de información para el electorado mexicano. Los spots fueron más positivos aunque, paradójicamente, carecieron de información detallada que abonara - tal y como lo establece la justificación legislativa a la obtención de esta prerrogativa-, a la discusión pública durante el proceso electoral.

Figura 2. Proporción de spots de acuerdo con el contenido de sus proposiciones.

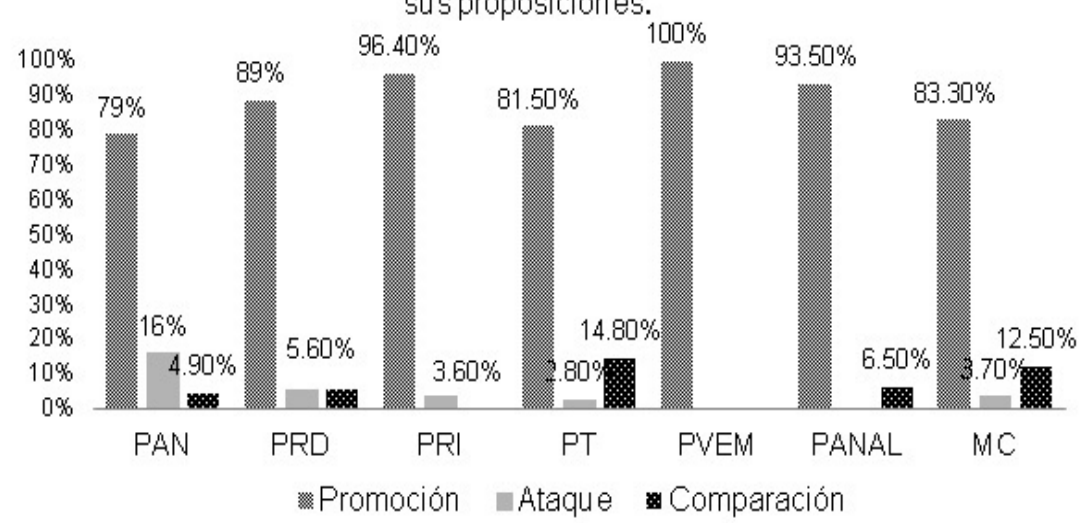

Nota: la proposición de cada spot se analizó según la siguiente definición:

Orientación de la proposición: la orientación significa la dirección hacía la cual apunta la proposición al momento de definir una situación en particular.

Promoción: identificación explícita de las cualidades del candidato o partido patrocinador.

Ataque: referencia explícita en sentido negativo de las características profesionales y/o personales de uno o más oponentes.

Comparación: comparación entre el partido/candidato patrocinador del mensaje y uno o más de sus oponentes (nota: es necesaria la mención expresa de ambos). 
Esta revista forma parte del acervo de la Biblioteca Jurídica Virtual del Instituto de Investigaciones Jurídicas de la UNAM

De acuerdo con nuestro estudio, el $89 \%$ de los spots se destina a promover al candidato o partido, las más de las veces con presentaciones discursivas unidireccionales en lugar de proposiciones que buscan un diálogo entre partidos políticos o con el electorado. El partido que sólo promovió su imagen fue el PVEM, ocupando la totalidad de su tiempo para promoverse como entidad política. De hecho, en los spots publicitados donde expone una situación pública (por ejemplo, falta de medicinas en las farmacias o el cobro de cuotas en las escuelas), no emite mensajes contra ningún actor político en particular.

Muy de lejos del número de spots que utilizan la promoción como estrategia del mensaje, los spots comparativos fueron los menos utilizados por los partidos políticos (4.5\%). El partido que realizó más comparaciones fue el PT (14.8\%). Esto se debe, entre otras cosas, a que el PT buscó contrastar más la experiencia de gobierno de su candidato (AMLO) con la de sus oponentes.

Los efectos restrictivos de la reforma electoral de 2007-2008, en donde se estableció la prohibición constitucional del uso de este tipo de campañas, se observan en la tendencia a disminuir los spots negativos en las campañas electorales en México. Mientras en 2006 dichos spots representaron el $27 \%$ de la producción, en 2009 disminuyó a $10 \%,{ }^{7}$ y en 2012 alcanzaron solamente el $6.5 \% .{ }^{8}$

En 2012 el PAN fue el partido que más utilizó esta estrategia, pues $16 \%$ de sus spots tenían este propósito. Tal magnitud, es notoriamente mayor al 5.6\% destinado por el PRD; el 3.6\% del PRI; el 3.7\% del PT, y el $4.2 \%$ de MC. Los ataques hechos por el PAN se dirigieron más hacia los candidatos (84.6\%) que a los partidos políticos (15.6\%). Los ataques del PAN pueden explicarse como parte de los cambios

7 Juárez Gámiz, Julio, “El papel de la publicidad política en la nueva ley electoral: una mirada crítica”, Revista Sociológica de la Universidad Autónoma Metropolitana, núm. 72, 2010.

8 En la literatura no hay consenso respecto a los efectos en el electorado del uso de spots negativos. Por un lado, algunos autores afirman que dichos spots tienden a disminuir el interés del electorado en la política y, por tanto, a acudir menos a las urnas (Ansolabehere, Stephen y Iyengar, Shanto, Going Negative: How Attack Ads Shrink and Polarize the Electorate, Nueva York, Free Press, 1995). Por otro, hay una corriente crítica a esta posición y afirma que no hay relación entre el tono de la campaña y los resultados de la participación electoral, es decir, no encontraron evidencia concluyente sobre la desmovilización del electorado con este tipo de campaña (Freedman, Paul y Goldstein, Ken, "Measuring Media Exposure and the Effects of Negative Campaign Ads", American Journal of Political Science, vol. 43, núm. 3, 1999). 
Esta revista forma parte del acervo de la Biblioteca Jurídica Virtual del Instituto de Investigaciones Jurídicas de la UNAM

que, en materia de preferencias electorales, se fueron dando durante la campaña, pasando del segundo al tercer lugar en las preferencias. ${ }^{9}$ Sus ataques se destinaron tanto al primero como al segundo lugar, ya fuera el PRI o el PRD.

\section{Personalización de la política}

La naturaleza de las elecciones presidenciales en las democracias modernas convierte a la figura presidencial en el eje discusivo más importante de la campaña política. Incluso en los casos como el mexicano en donde el Congreso y otros actores tienen un papel central en la vida política del país, la figura del presidente es uno de los símbolos que acaparan la publicidad durante las campañas. Uno de los principales hallazgos de este artículo es la preponderancia de la imagen de los candidatos a la presidencia de la República en el contenido de los spots, que se refleja en detrimento de los candidatos al Congreso.

Aunque la legislación vigente (Cofipe, artículo 60) estipula que "en el proceso electoral en que se renueven el Poder Ejecutivo de la Unión y las dos Cámaras del Congreso, cada partido deberá destinar, al menos, un $30 \%$ de los mensajes a la campaña de uno de los poderes", en realidad no se aprecia con claridad el porcentaje destinado ya sea a candidatos presidenciales o al Congreso, independientemente de si uno observa el contenido expreso del mensaje o la rúbrica insertada por el partido que lo produce.

Del total de los spots del censo, se detectó en 250 (81\%) la presencia de alguno de los cuatro candidatos a la presidencia, el resto de producciones, 58 (19\%), estuvieron destinadas a mensajes en donde los candidatos a la presidencia no aparecían, sin que esto significara que fueran destinados expresamente a las campañas de senadores o diputados.

De acuerdo con nuestra investigación, en el $27 \%$ del total de los spots (85 de 308) apareció explícitamente una leyenda de llamado al voto para diputados y senadores, sin embargo, esto no significa que esos spots fueran dedicados a la promoción de los candidatos al Congreso, pues la gran mayoría se utilizó para promover la figura presidencial o para hacer campaña de ataque contra sus demás contrincantes.

9 Encuesta nacional Grupo Reforma, "Cierra brecha AMLO”, 31 de mayo de 2012, consultado el 10 de agosto de 2012 en http://gruporeforma-blogs.com/encuestas/? $p=1590$. 


\section{Figura 3. Porcentaje intrapartidista de spots rubricados.}

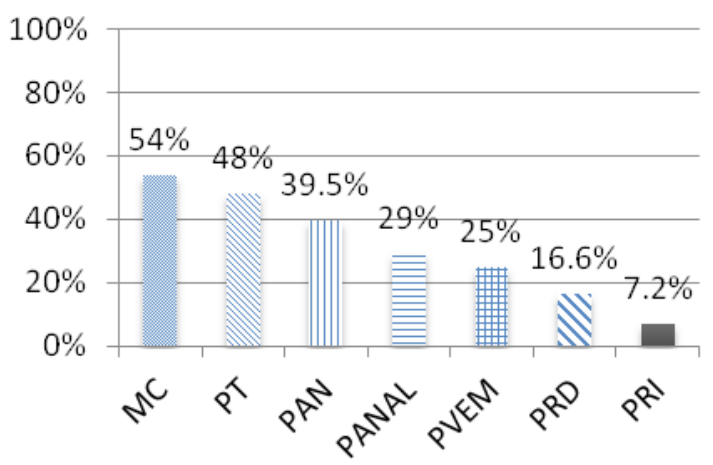

En suma, la presencia de rúbricas llamando a votar por diputados y senadores no significaba directamente que el contenido del spot hiciera referencia, en audio o en video, a los candidatos al Congreso. Paralelamente, muchos spots en donde se llamaba a votar por los candidatos al Congreso no aparecían rubricados.

\section{Conclusiones}

Con base en los datos antes expuestos, es posible listar una serie de conclusiones respecto a los efectos de la reforma electoral 2007-2008 en el uso del spot publicitario como herramienta de comunicación política en las elecciones federales de 2012.

Primero, la evidencia empírica apunta que el nivel de información política presentada por los partidos políticos en su publicidad es escaso y, cuando llega a aparecer, es superficial. Uno de los hallazgos más importantes de la investigación es que más de la mitad de las producciones audiovisuales realizadas por los partidos no se refieren a ningún tema que los mismos postulan en su plataforma electoral. En este sentido, es posible inferir que el electorado que recibe la información de los spots políticos se entera más de los atributos y defectos personales de los contendientes, que de información política referente a los principales retos y problemas que enfrenta la sociedad y los posicionamientos concretos de los candidatos frente a ellos. 
Segundo, a partir de la reforma electoral 2007-2008 se percibe una disminución de las campañas negativas y de contraste, aunque esto no se ha traducido en la generación de piezas de publicidad política más informativas. De acuerdo con los datos de esta investigación, han aumentado los spots políticos de promoción que resaltan características insustanciales de los candidatos de manera unilateral. Como lo demuestra el análisis de contenido, estos spots se caracterizan por privilegiar un monólogo antes que una conversación. Por tanto, en los spots de la elección federal 2012 hay una ausencia de producciones con contenido sustancial, así como de referencias explícitas a las plataformas programáticas propias o de otros partidos políticos.

Tercero, la publicidad política televisiva favorece la personalización de la política en detrimento de la difusión de plataformas electorales y propuestas que diferencien la oferta política de los contendientes. Los datos presentados en este estudio advierten que los partidos políticos utilizan la publicidad política para, principalmente, promover la imagen de sus candidatos a la presidencia. Nuestro análisis da cuenta de que ocho de cada diez spots fueron producidos para promover a los candidatos a la presidencia, reduciendo así la presencia de las campañas al Senado y a la Cámara de los Diputados en la publicidad política de los partidos.

Finalmente, de acuerdo con los hallazgos arriba expuestos, a continuación enlistamos cuatro recomendaciones:

- Explorar otros formatos de comunicación política diferentes al compacto modelo de los spots de 30 segundos. La inclusión de otros formatos de publicidad política diferentes al spot de 30 segundos es legalmente plausible, toda vez que la legislación contempla producciones de hasta dos minutos por pieza. Lo anterior sería benéfico, principalmente para el electorado, pues orilla a los partidos políticos a desarrollar temáticas complejas y profundas que beneficiarían una mayor calidad de información y debate político.

- Redistribuir el tiempo oficial para favorecer un uso estratégico de la publicidad y no la repetición masiva de mensajes. De acuerdo con nuestros datos algunos partidos políticos producen una muy limitada cantidad de spots durante la elección, lo que trae como consecuencia una sobreexposición de dichos mensajes en el electorado. Lo anterior puede producir un efecto no deseado de sa- 
Esta revista forma parte del acervo de la Biblioteca Jurídica Virtual del Instituto de Investigaciones Jurídicas de la UNAM

turación entre la opinión pública, en este sentido, el modelo de comunicación política vigente no favorece la distribución estratégica del tiempo aire, pues más bien está anclado a la idea de la repetición masiva y no repara en la importancia de segmentar las audiencias. Por tanto, es necesario modificar la premisa de dicha repetición de mensajes por una distribución estratégica del tiempo aire, capaz de controlar la segmentación de mensajes por variables espacio-temporales.

- Reglamentar la inclusión de temas sustantivos en la discusión. De acuerdo con la investigación es posible inferir que los partidos políticos no tienen incentivos para incluir ningún tipo de información política en particular en su publicidad, por lo que la gran mayoría de los spots se refieren a información inútil para que el electorado tome su decisión. En este sentido, se recomienda crear reglamentaciones (normativas) para que los partidos políticos destinen una parte de su publicidad a retomar temas y propuestas puntuales que desarrollan en su plataforma electoral.

- Precisar la diferencia entre campaña negativa y de contraste. De acuerdo con el presente estudio, los spots de promoción son cada vez más utilizados por los partidos políticos en comparación a los de contraste. Sin embargo, la literatura apunta que las campañas de contraste (comparar uno o varios aspectos de un partido o candidato con sus oponentes) son de mayor utilidad para el electorado en relación con las de promoción o de ataque directo, puesto que permite cotejar y diferenciar propuestas entre candidatos. Sin embargo, incentivar el uso de campañas de contraste significa reconocer que contrastar propuestas no es un equivalente a la calumnia o la difamación, pues es posible producir publicidad crítica sin denostar al oponente.

\section{Fuentes consultadas}

Ansolabehere, S. e Inyegar, S., Going Negative: How Attack Ads Shrink and Polarize the Electorate, Nueva York, Free Press, 1995.

Freedman, Paul y Goldstein, Ken, "Measuring Media Exposure and the Effects of Negative Campaign Ads", American Journal of Political Science, vol. 43, núm. 3, 1999. 
Esta revista forma parte del acervo de la Biblioteca Jurídica Virtual del Instituto de Investigaciones Jurídicas de la UNAM

JuÁRez GÁmiz, Julio, “El papel de la publicidad política en la nueva ley electoral: una mirada crítica”, Revista Sociológica, Universidad Autónoma Metropolitana, núm. 72, 2010.

\section{Otros documentos}

BGC-Excélsior, 23 de abril de 2012. Encuesta Nacional.

Constitución Política de los Estados Unidos Mexicanos, http://www. diputados.gob.mx/LeyesBiblio/pdf/1.pdf.

Código Federal de Instituciones y Procedimientos Electorales, $h t t p: / /$ info4.juridicas.unam.mx/ijure/tcfed/4.htm.

Encuesta nacional Grupo Reforma, "Primeros efectos de campaña", 6 de mayo de 2012, consultado el 10 de agosto de 2012, http://gruporeforma-blogs.com/encuestas/? $p=1288$.

Encuesta nacional Grupo Reforma, "Cierra brecha AMLO", 31 de mayo de 2012, consultado el 10 de agosto de 2012, http://gruporeforma-blogs.com/encuestas/? $p=1590$.

Resultados de la encuesta poselectoral realizada por el Centro de Investigación y Docencia Económicas, 13 de octubre de 2009. Encuesta nacional. 